\title{
ANALISIS FAKTOR-FAKTOR YANG MEMPENGARUHI PRODUKSI KELAPA SAWIT RAKYAT POLA SWADAYA DI KABUPATEN KAMPAR-RIAU
}

\author{
Anto Ariyanto, Rini Nizar dan Enny Mutryarny ${ }^{*}$ \\ Universitas Lancang Kuning Pekanbaru
}

\begin{abstract}
ABSTRAK
Kelapa sawit merupakan salah satu komoditas yang potensial yang banyak dibudidayakan di Kabupaten Kampar Riau. Untuk dapat tumbuh dan berproduksi dengan baik, kelapa sawit membutuhkan pemanfaatan faktor-faktor produksi yang optimal. Penelitian ini bertujuan untuk mengetahui faktor-faktor yang mempengaruhi produksi kelapa sawit rakyat pada Pola Swadaya di Kabupaten Kampar Riau. Pengkajian dilaksanakan di Kecamatan Tapung dan Tapung Hilir Kabupaten Kampar Riau pada bulan April 2017. Pemilihan lokasi dilakukan secara sengaja dengan responden berjumlah 32 orang petani. Responden yang dipilih merupakan petani kelapa sawit yang telah menghasilkan (umur tanaman diatas 3 tahun). Pengumpulan data dilakukan dengan metode survei berupa data primer dan data sekunder. Data primer diperoleh melalui informasi yang dihimpun dari responden menggunakan daftar pertanyaan yang disusun secara terstruktur (kuesioner) meliputi identitas responden, kepemilikan lahan, faktor produksi kelapa sawit dan kelembagaan. Sedangkan data skunder diperoleh dari Badan Pusat Statistik dan dinas instansi terkait. Data yang diperoleh di analisis dengan menggunakan model fungsi produksi CobbDouglas yang diolah dengan teknik analisis OLS (Ordinary Least Square). Hasil penelitian menunjukkan bahwa faktor yang mempengaruhi produksi kelapa sawit rakyat dengan pola swadaya di Kabupaten Kampar Riau adalah umur tanaman berpengaruh nyata positif sebesar $31.85 \%$, dan penggunaan pupuk urea berpengaruh nyata positif sebesar $33.24 \%$.
\end{abstract}

Kata Kunci : faktor produksi, kelapa sawit, pola swadaya

\section{PENDAHULUAN}

Di Indonesia, keterlibatan aktif dari petani rakyat dalam budidaya kelapa sawit ini pada awalnya merupakan bagian dari kebijakan pemerintah melalui program transmigrasi. Program transmigrasi merupakan program perpindahan penduduk dari Jawa ke Sumatera, Kalimantan dan pulau-pulau kurang padat lainnya yang didukung melalui budidaya kelapa sawit dan kegiatan ekonomi lainnya dalam upaya mewujudkan pemberdayaan masyarakat dan pembangunan ekonomi di daerah pedesaan (Gatto et al. 2014). Selanjutnya petani yang dilibatkan dalam budidaya kelapa sawit tersebut terikat melalui hubungan kontrak dengan perusahaan-perusahaan negara dan swasta (Hasnah et al. 2004).

Selanjutnya dalam budidaya kelapa sawit di Indonesia terdiri dari beberapa tipe petani rakyat. Mereka dibedakan dalam hal bagaimana petani berhubungan dengan produksi dan pemasaran TBS. Secara garis besar kita dapat membedakan menjadi dua tipe petani, yaitu petani pola kemitraan PIR dan petani pola swadaya (Gambar 1). Petani pola kemitraan PIR adalah petani yang memulai budidaya kelapa sawit dengan skema pengelolaan dibawah binaan pemerintah atau swasta dan kedua, mereka yang memutuskan untuk mengadopsi pengelolaan kelapa sawit tersebut secara mandiri (Euler et al. 2015). Pada petani dalam 
binaan, mereka memasok produk mereka ke perusahaan perkebunan atau pabrik kelapa sawit. Hubungan mereka didasarkan pada kontrak, sedangkan perusahaan perkebunan tetap bertanggung jawab untuk bantuan teknis dan pemasaran. Sedangkan petani pola mandiri (swadaya) tidak terikat atau terikat kontrak dengan untuk perusahaan perkebunan atau pun pabrik CPO. Mereka bebas untuk menjual kepada pembeli apapun. Dalam prakteknya, mereka menjual secara langsung ke pabrik atau untuk pedagang lokal (Tengkulak). Jika petani swadaya tidak memiliki sarana transportasi, mereka dapat mengandalkan eksklusif pada satu pedagang tertentu atau pada pabrik terdekat (Papenfus 2000). Dalam penelitian ini fokus pada perkebunan rakyat pola swadaya.

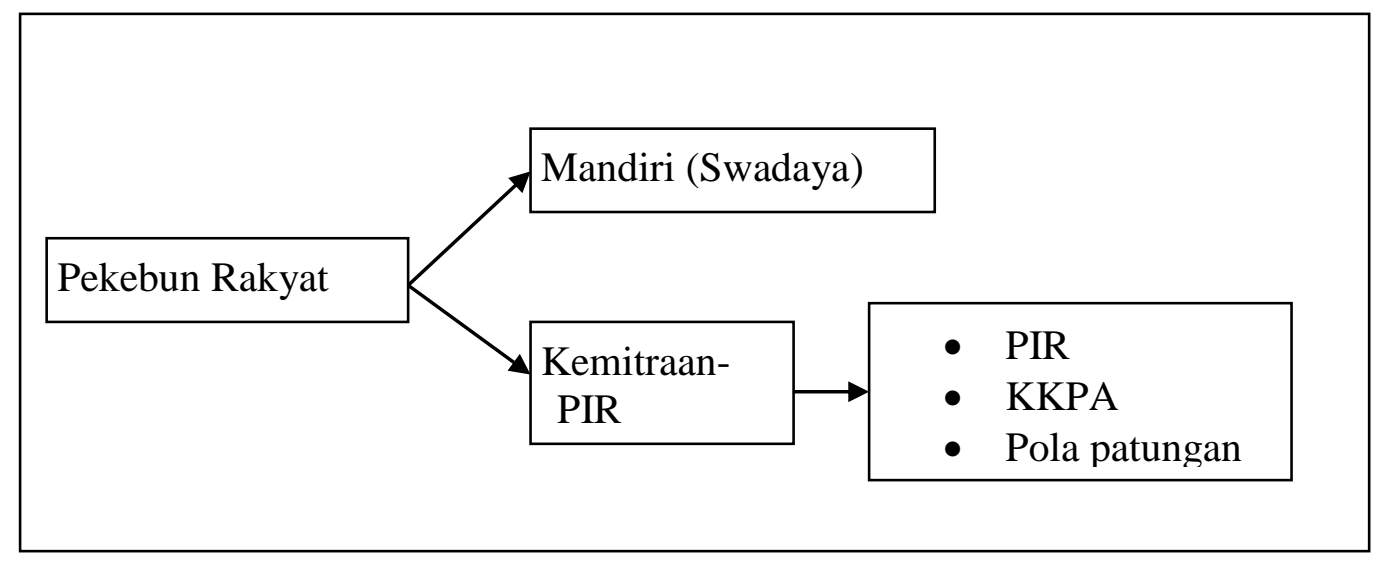

Gambar 1. Pola pengelolaan perkebunan rakyat di Indonesia

Bukti empiris menunjukkan antara tahun 2000-2009, laju ekspansi kelapa sawit rakyat di Indonesia dengan tingkat pertumbuhan tahunan $11.12 \%$, jauh lebih tinggi dari perkebunan pemerintah $(0.37 \%)$ dan perusahaan swasta $(5.45 \%)$ (Dewan Minyak Sawit Indonesia 2010). Bahkan pada rentang tahun 1980-1997 laju peningkatan areal perkebunan kelapa sawit rakyat di Indonesia mencapai 46,85 persen per tahun, yang merupakan masamasa ekspansi perkebunan rakyat terbesar (Ditjenbun 2015). Dari beberapa kajian, diperkirakan bahwa perkebunan sawit rakyat ini akan mendominasi produksi minyak sawit secara keseluruhan di Indonesia pada masa mendatang (Vermeulen dan Goad 2006; Euler et al. 2016). Namun peningkatan luas lahan perkebunan kelapa sawit rakyat tersebut tidak diikuti oleh peningkatan produktivitas yang optimal.

Kabupaten Kampar Riau merupakan salah satu kabupaten di provinsi Riau yang memiliki potensi tanaman perkebunan kelapa sawit yang cukup besar, yaitu dengan luas 225,606 hektar dengan jumlah produksi sebesar 2.705.801 ton atau sekitar 16.99 persen dari total produksi kelapa sawit di Provinsi Riau (BPS, 2017). Hal ini menunjukkan bahwa kelapa sawit sebagai salah satu komoditas primadona di kabupaten Kampar yang memiliki peranan penting dalam perekonomian di daerah ini, sehingga perlu dilakukan penelitian untuk mengetahui faktor-faktor penentu produksi yang mempengaruhinya. Penelitian ini bertujuan untuk mengetahui faktor-faktor yang mempengaruhi produksi kelapa sawit rakyat di Kabupaten Kampar Provinsi Riau sehingga diharapkan dapat dibentuk sebuah sistem perkebunan kelapa sawit rakyat dengan tingkat produksi yang tinggi. 


\section{BAHAN DAN METODA}

Pengkajian dilaksanakan di Kecamatan Tapung dan Tapung Hilir Kabupaten Kampar Riau pada bulan April 2017. Pemilihan lokasi dilakukan secara sengaja dengan responden berjumlah 32 orang. Responden yang dipilih merupakan petani kelapa sawit yang telah menghasilkan (umur tanaman diatas 3 tahun). Pengkajian ini dilaksanakan pada perkebunan rakyat pada pola swadaya. Pengumpulan data dilakukan dengan metode survei berupa data primer dan data sekunder. Data primer diperoleh melalui informasi yang dihimpun dari responden menggunakan daftar pertanyaan yang disusun secara terstruktur (kuesioner) meliputi identitas responden, kelembagaan, kepemilikan lahan, serta faktor produksi kelapa sawit sedangkan data sekunder diperoleh dari Badan Pusat Statistik dan dinas instansi terkait. Untuk menentukan faktor yang berpengaruh terhadap produksi kelapa sawit digunakan analisis kuantitatif melalui pendungaan Ordinary Least Square (OLS). Analisis ini dilakukan melalui pendekatan fungsi produksi bertipe Cobb-Douglas yaitu suatu fungsi atau persamaan yang melibatkan dua variabel atau lebih, variabel yang satu disebut variabel independent (Y) dan yang lain disebut variabel dependent (X) yang secara matematis formulasinya dapat dituliskan sebagai berikut :

$$
\mathrm{Y}=\mathrm{aX}{ }^{\mathrm{b} 1} \mathrm{X} 2^{\mathrm{b} 2} \mathrm{X} 3^{\mathrm{b} 3} \mathrm{X} 4^{\mathrm{b} 4} \mathrm{X} 5^{\mathrm{b} 5} \mathrm{X} 6^{\mathrm{b} 6} \mathrm{e}^{\mathrm{u}}
$$

Agar fungsi produksi Cobb-Duoglas dapat diestimasi dengan metode OLS maka diubah kedalam bentuk logaritma natural sebagai berikut:

$$
\begin{aligned}
\mathrm{Ln} Y=\mathrm{Lna}+\mathrm{b} 1 \mathrm{LnX} 1 & +\mathrm{b} 2 \operatorname{LnX} 2+\mathrm{b} 3 \operatorname{LnX} 3+\mathrm{b} 4 \operatorname{LnX} 4+\mathrm{b} 5 \operatorname{LnX} 5+\mathrm{b} 6 \operatorname{LnX} 6+\mathrm{u} \\
\text { dimana: } \mathrm{Y} & =\text { produksi kelapa sawit }(\mathrm{kg}) \\
\mathrm{X} 1 & =\text { luas lahan }(\mathrm{ha}) \\
\mathrm{X} 2 & =\text { jumlah populasi tanaman (pohon) } \\
\mathrm{X} 3 & =\text { Umur tanaman }(\operatorname{tahun}) \\
\mathrm{X} 4 & =\text { jumlah pestisida }(\mathrm{ml}) \\
\mathrm{X} 5 & =\text { jumlah pupuk urea }(\mathrm{kg}) \\
\mathrm{X} 6 & =\text { jumlah pupuk SP36 }(\mathrm{kg}) \\
\mathrm{X} 7 & =\text { jumlah pupuk KCL }(\mathrm{kg}) \\
\mathrm{a} & =\text { Intersep } \\
\mathrm{bi} & =\text { Koefisien } \\
\mathrm{e} & =\text { Logaritma regresi } \\
\mathrm{u} & =\text { Kesalahan pengganggu }
\end{aligned}
$$

Untuk mengetahui goodness of fit dari model dilihat dari nilai $\mathrm{R}^{2}$. Model dikatakan baik apabila nilai $\mathrm{R}^{2}$ mendekati 1 . Untuk mengetahui pengaruh dari variabel bebas terhadap variabel terikat secara serentak dilakukan dengan pengu-jian uji F. Selanjutnya untuk mengetahui pengaruh dari masing-masing variabel bebas secara individu/parsial digunakan uji t.

\section{HASIL DAN PEMBAHASAN}

\section{Karakteristik Responden}

Petani kelapa sawit rakyat pola swadaya di Kabupaten Kampar Riau didominasi oleh petani laki-laki $(90.6 \%$ ) yang berumur 40-59 tahun $(59.4 \%)$ dengan jumlah tanggungan keluarga paling banyak berkisar 3-5 orang (Tabel 1). Artinya secara umum petani berada 
pada usia produktif dimana usia produktif berada pada kisaran usia 15-55 (Rosman, 2000). Dimana pada usia produktif, seseorang akan memiliki semangat yang tinggi dalam melakukan usahanya serta lebih cepat untuk melakukan adopsi inovasi (Soekartawi, 2005).

Petani kelapa sawit rakyat pola swadaya di Kabupaten Kampar Riau rata-rata mengenyam pendidikan formal selama 7.9 tahun dan bila diasumsikan setiap orang menyelesaikan setiap jenjang tepat waktu maka dapat dikatakan rata-rata petani telah menamatkan Sekolah Dasar (SD) namun belum menamatkan Sekolah Menengah Pertama (SMP). Hal ini menunjukkan bahwa tingkat pendidikan petani kelapa sawit rakyat pola swadaya relatif masih rendah.

Tabel 1. Karakteristik petani kelapa sawit rakyat pola swadaya di Kabupaten Kampar Riau tahun 2017.

\begin{tabular}{|c|c|c|c|c|c|}
\hline No & Karakteristik & Kelompok & Jumlah (orang) & Persentase $(\%)$ & Rata-rata \\
\hline \multirow[t]{2}{*}{1.} & Jenis kelamin & Laki-laki & 29 & 90.6 & \\
\hline & & Perempuan & 3 & 9.4 & \\
\hline \multirow[t]{3}{*}{2.} & Umur (tahun) & $20-39$ & 5 & 15.6 & 52.3 \\
\hline & & $40-59$ & 19 & 59.4 & \\
\hline & & $60-79$ & 8 & 25.0 & \\
\hline \multirow[t]{3}{*}{3.} & Jumlah anggota & $0-2$ & 4 & 12.5 & 4.0 \\
\hline & rumah tangga & $3-5$ & 24 & 75.0 & \\
\hline & & $6-8$ & 4 & 12.5 & \\
\hline \multirow[t]{3}{*}{4.} & Pendidikan & $0-5$ & 1 & 3.1 & 7.9 \\
\hline & & $6-11$ & 24 & 75.0 & \\
\hline & & $12-17$ & 7 & 21.9 & \\
\hline
\end{tabular}

Sumber: data primer diolah 2017.

\section{Karakteristik Usahatani}

Dilihat dari karakteristik usahatani, terlihat luas lahan rata-rata yang diusahakan oleh petani rakyat pola swadaya untuk berusahatani kelapa sawit di Kecamatan Tapung hilir dan Tapung Kabupaten Kampar Riau seluas 3.92 ha dengan jumlah populasi rata-rata berjumlah 555.19 pohon. Bila dikonversikan dalam satuan per hektar, maka jumlah populasi tanaman kelapa sawit petani pola swadaya di Kabupaten Kampar Riau berjumlah 238.34 pohon/hektar. Jumlah ini lebih banyak bila dibandingkan dengan jumlah populasi pohon produktif yang ditanam dengan susunan paling ekonomis yaitu 143 pohon per hektar ( Fauzi, 2002 dalam Wijayanti dan Mudakir, 2013), dengan jumlah produksi sekitar $19.961 \mathrm{~kg} / \mathrm{ha} / \mathrm{tahun}$. Pada dasarnya sebagian besar petani swadaya sudah memahami ukuran serta jarak tanam yang ideal, namun implemantasinya kebun swadaya menginginkan jumlah dan volume tanaman yang lebih banyak dengan harapan akan menghasilkan panen yang banyak. Hal ini tentu tidak 
selalu berbanding lurus antara jumlah tanaman dengan produksi. Seharusnya dilakukan adalah jarak dan pola tanam yang tepat agar pertumbuhan dan perolehan cahaya matahari akan berimbang sehingga produksi akan optimal.

Tabel 2. Karakteristik usahatani kelapa sawit di Kabupaten Kampar Riau tahun 2017.

\begin{tabular}{llc}
\hline No & Karakteristik & Rata-rata \\
\hline 1 & Luas lahan (ha) & 3.92 \\
2 & Jumlah populasi (pohon) & 555.19 \\
3 & Umur tanaman (tahun) & 13.47 \\
4 & Produksi (kg/ha/tahun) & 19.961 \\
5 & Frekuensi pemupukan (kali/thn) & 1.37 \\
6 & Jumlah penggunaan pupuk (kg/ha/tahun) & \\
& $-\quad$ Urea & 517.13 \\
& $-\quad$ SP36 & 465.74 \\
& $-\quad$ KCL & 490.21 \\
& $-\quad$ Dolomit & 418.69 \\
7 & Jumlah penggunaan pestisida (ltr/ha/tahun) & 7.81 \\
8 & Curahan tenaga kerja (HOK/thn) & 74.61 \\
\hline
\end{tabular}

Sumber : data primer 2017.

Rata-rata umur kelapa sawit yang diusahakan petani adalah 13.47 tahun. Bila berdasarkan umur tanaman maka kelapa sawit petani pola swadaya berada pada kelompok tanaman dewasa. Pada masa berbuah, kelapa sawit membutuhkan perawatan seperti pemupukan dan pengendalian organisme penganggu tanaman (OPT). Dalam satu tahun kebun swadaya rata-rata petani melakukan pemupukan sebanyak 1.57 kali dengan jumlah pupuk urea $517.13 \mathrm{~kg} / \mathrm{ha} /$ tahun, pupuk SP36 $465.74 \mathrm{~kg} / \mathrm{ha} / \mathrm{tahun}, \mathrm{KCL} 490.21 \mathrm{~kg} / \mathrm{ha} / \mathrm{tahun}$ dan dolomit $418.69 \mathrm{~kg} / \mathrm{ha} /$ tahun. Apabila dikonversi per pohon penggunaan pupuk urea sebesar 0,93 kg/Pohon, SP36 sebesar 0,84 Kg/Pohon dan KCL sebesar 0,88 Kg/Pohon. Pada kebun swadaya pada umumnya aplikasi pupuk dilakukan bergantung pada ketersediaan dana, sehingga tidak memperhatikan ketepatan waktu, volume, dan jenis pupuk.

Kegiatan pemupukan ini dilakukan bertujuan untuk menambah ketersediaan unsur hara di dalam tanah terutama agar tanaman dapat menyerapnya sesuai dengan kebutuhan (Mursidah, 2009). Dalam mengendalikan organisme pengganggu tanaman, petani melakukan kegiatan penyemprotan gulma dan hama. Jumlah pestisida yang digunakan oleh petani dalam pemeliharaan kelapa sawitnya sejumlah $7.81 \mathrm{ltr} / \mathrm{ha} / \mathrm{thn}$ terdiri dari herbisida dan insektisida. Jenis pupuk dan pestisida yang digunakan oleh petani adalah pupuk dan pestisida yang tersedia di kios-kios pertanian di desa mereka. Proses budidaya pada petani pola swadaya seringkali standar budidaya diabaikan, dalam arti hanya ingin memanen hasil tetapi tidak memperhatikan bibit unggul, perawatan yang baik, dan pemupukan yang tepat. Fakta dilapangan bahwa tanaman kelapa sawit pada pola swadaya setelah tanam sangat kurang perawatan, dan ketika akan panen baru dilakukan perawatan, padahal perawatan hari ini akan berdampak signifikan 6 bulan yang akan datang dan seterusnya. 
Jumlah tenaga kerja yang digunakan oleh petani sawit pola swadaya berjumlah $74.61 \mathrm{HOK} /$ tahun, yang umumnya berasal dari dalam keluarga. Tenaga kerja ini digunakan pada kegiatan pemupukan, penyiangan, penyemprotan hama dan penyakit serta panen dan pengangkutan hasil panen. Rata-rata besar upah per HOK adalah Rp. 65.000 untuk perawatan sedangkan upah panen sebesar Rp. 80.000/ton dan bervariasi tergantung ketinggian pohon kelapa sawit, hal ini didasarkan pada tingkat kesulitan dalam melakukan panen. Sedangkan harga TBS berkisar 1.500/kg untuk usia tanaman lebih dari 10 tahun dan Rp. 1.200/kg untuk usia tanaman kurang dari 10 Tahun.

Kelembagaan tani pada petani pola swadaya tidak terbentuk dengan baik, pada umumnya petani berhubungan langsung dengan tengkulak dalam menjual hasil TBS. Pola ini sangat mengikat posisi petani karena diberi kemudahan dalam berhutang atau meminjam dana, disisi lain harga ditentukan oleh tengkulak, dampaknya adalah petani secara jangka pendek atau panjang tidak dapat meninkmati harga yang lebih baik sebelum lunas hutangnya.

\section{Faktor-Faktor yang Mempengaruhi Produksi Kelapa Sawit Rakyat Pola Swadaya}

Hasil analisis regresi model menunjukkan bahwa nilai koefisien determinasi $\left(\mathrm{R}^{2}\right)$ diperoleh sebesar 0.86 artinya secara bersama-sama variabel luas lahan, jumlah populasi, umur tanaman, jumlah pestisida, curahan tenaga kerja,frekuensi pemupukan dan jenis lahan mempengaruhi produksi kelapa sawit sebesar atau $86 \%$ sedangkan sisanya dipengaruhi oleh faktor lain yang belum dimasukkan dalam model. Nilai F hitung (20.98) (signifikan pada taraf kepercayaan 80\%) menunjukkan bahwa semua variabel yang ada di dalam model analisis secara bersama-sama berpengaruh terhadap produksi kelapa sawit (Tabel 3). Dengan demikian model yang digunakan dalam estimasi fungsi produksi ini dapat dikategorikan telah memadai.

Tabel 3. Hasil analisis regresi faktor-faktor yang mempengaruhi produksi kelapa sawit pola swadaya di Kabupaten Kampar Riau tahun 2017.

\begin{tabular}{lcc}
\hline \multicolumn{1}{c}{ Variabel } & bi & t hitung \\
\hline Konstanta & 5.322 & 0.73 \\
Luas Lahan (X1) & 0.100 & 0,07 \\
Jumlah pohon (X2) & 0,274 & 0,20 \\
Umur tanaman (X3) *** & 0,3185 & 1,36 \\
Pestisida (X4) & 0,1924 & 1,29 \\
Urea (X5) *** & 0,3324 & 1,51 \\
SP36 (X6) & $-0,3040$ & $-0,58$ \\
KCL (X7) & 0,3566 & 0,73 \\
\hline
\end{tabular}

$\mathrm{R}^{2}=0.86$

F - Hitung $=20,98$

Keterangan : ***signifikan pada taraf kepercayaan $80 \%$,

Sumber : data primer diolah 2017 
Berdasarkan output dari Minitab pada Tabel di atas, maka secara matematis dapat ditulis model regresi antara variabel produksi dengan variabel yang mempengaruhinya dalam persamaan berikut:

$$
\begin{aligned}
& \operatorname{Ln}(Y)=5,32+0,10 \operatorname{Ln}(X 1)+0,27 \operatorname{Ln}(X 2)+0,319 \operatorname{Ln}(X 3)+0,192 \operatorname{Ln}(X 4) \\
&+0,332 \operatorname{Ln}(X 5)-0,304 \operatorname{Ln}(X 6)+0,357 \operatorname{Ln}(X 7)
\end{aligned}
$$

Secara parsial analisis terhadap variabel bebas yang mempengaruhi produksi menunjukkan bahwa variabel umur tanaman dan jumlah pupuk urea berpengaruh nyata terhadap jumlah produksi kelapa sawit. Sedangkan variabel luas lahan, jumlah populasi kelapa sawit, jumlah pestisida, jumlah pupuk SP36 dan jumlah pupuk KCL tidak berpengaruh nyata terhadap produksi kelapa sawit.

Umur tanaman berpengaruh nyata positif terhadap produksi kelapa sawit rakyat di Kabupaten Kampar Riau. Dengan asumsi variabel yang lain ceteris paribus maka peningkatan umur tanaman sebesar 1 persen akan meningkatkan total produksi sebesar 31.85 persen. Umur tanaman kelapa sawit petani pola swadaya rata-rata berumur 13.47 tahun hal ini berarti kelapa sawit petani mulai memasuki masa produktivitas maksimal karena produktivitas maksimal kelapa sawit dapat dicapai ketika tanaman dicapai saat rata-rata umur tanaman 15 tahun ( Lubis,1992 dalam Prihutami, 2011).

Jumlah penggunaan pupuk urea juga berpengaruh nyata positif terhadap produksi kelapa sawit pada pola swadaya pada taraf kepercayaan $80 \%$. Dengan asumsi variabel yang lain ceteris paribus maka peningkatan jumlah tenaga kerja sebesar 1 persen akan meningkatkan total produksi sebesar 33,24 persen. Hal ini menunjukkan bahwa pemupukan urea merupakan faktor produksi yang penting dan perlu diperhitungkan dalam proses produksi. Kegiatan pemupukan merupakan salah satu kegiatan perawatan tanaman yang bertujuan untuk mendapatkan target produksi Tandan Buah Segar (TBS) yang optimal dan mendapatkan kualitas minyak yang baik (Adiwiganda dan Siahaan, 1994 dalam Prihutami, 2011). Menurut Puslitbangbun (2010) pemupukan kelapa sawit sebaiknya dilakukan 2-3 kali tergantung pada kondisi lahan, jumlah pupuk, umur dan kondisi tanaman.

\section{KESIMPULAN DAN SARAN}

\section{Kesimpulan}

Faktor produksi umur tanaman berpengaruh nyata positif sebesar $31.85 \%$ dan jumlah penggunaan pupuk urea berpengaruh nyata positif sebesar 33.24\%.

\section{Saran}

Tanaman kelapa sawit telah melewati masa produktivitas maksimal perlu dipertimbangkan untuk dilakukan peremajaan tanaman sehingga penggunaan faktor produksi pemupukan yang efisien 


\section{DAFTAR PUSTAKA}

Alwarritzi, W., T. Nnaseki, and Y. Chomei. 2015 Analysis of the factors influencing the technical efficiency among oil palm smallholder farmers in Indonesia. Procedia Environmental Science, 21, issn 1878-0296 (in-press).

Asnil, S., H.B. Tarmizi, dan W.A. Pratomo. 2010. Analisis Produksi Pendapatan dan Alih Fungsi Lahan di Kabupaten Labuhan Batu. http://jurnalmepaekonomi.blogspot. com. [3 Oktober 2012]

Daniel, M. 2002. Pengantar Ekonomi Pertanian. Penrbit PT. Bumi Aksara. Jakarta

Euler, M., Krishna, V., Schwarze, S., Siregar, H. and Qaim, M. 2015. Oil palm adoption, household welfare and nutrition among smallholder farmers in Indonesia. EFForTS Discussion Paper 12, Georg-August University of Göttingen, Göttingen, Germany, Georg-August University of Göttingen. Göttingen, Germany.

Euler. M, Hoffmann. MP, Fathoni. Z, dan Schwarze S. 2016. Exploring Yield Gaps in Smallholder Oil Palm Production Systems in Eastern Sumatra, Indonesia. Agricultural Systems 146 : 111-119

Euler, M., Schwarze, S., Siregar, H. and Qaim, M. 2016. Oil Palm Expansion among smallholder farmers in Sumatra, Indonesia. Journal of Agricultural Economics (in press).

Gatto, M., Wollni, M. and Qaim, M. 2015. Oil palm boom and land-use dynamics in Indonesia: The role of policies and socioeconomic factors. Land Use Policy 46: 292303.

Hasnah, Fleming, E., Coelli, T. 2004. Assessing the Performance of a Nucleus Estate and Smallholder Scheme for Oil Palm Production in West Sumatra: A Stochastic Frontier Analysis. Agricultural Systems (79) :17-3.

Listyanto. 2000. Budidaya Tanaman Sawit (Elaeis Guineensis Jacg) Di Lahan Gambut. http://www.biopz.com/index.[ 7 Juni 2012]

Mariyah. 2004. Analisis Kebutuhan Modal dan Tingkat Penyerapan Tenaga Kerja Di PT.REA Kaltim Plantations. Jurnal EPP 1 (2): 41:50

Mursidah. 2009. Optimalisasi Pendapatan Usahatani Kelapa Sawit. Jurnal EPP 6 (2): 9-15 Prihutami, N.D. 2011. Analisis Faktor Penentu Produksi Tandan Buah Segar (TBS) Tanaman Kelapa

Sawit di Sungai Bahaur Estate (SBHE) PT Bumitama Gunajaya Agro (PT BGA) Wilayah VI Metro Cempaga Kota Waringin Timur Kalimantan Tengah. Skripsi Departemen Agronomi dan Hortikultura Institut Pertanian Bogor.Bogor. ;115.

Puslitbangbun. 2010. Budidaya Kelapa Sawit. Pusat Penelitian dan Pengembangan Perkebunan. Pusat Penelitian dan Pengembangan Perkebunan. Badan Penelitian dan Pengembangan Pertanian. Kementerian Pertanian. Jakarta.

Rosman. 2000.Tingkat Produktfitas Kerja Terhadap Umur Petani di Indonesia. Jurnal Pertanian No $87: 12-19$

Sasongko, P.E. 2010. Studi Kesesuaian Lahan Potensial Untuk Tanaman Kelapa Sawit Di Kabupaten Blitar. Jurnal Pertanian MAPETA 7 (2): 72 - 134

Wijayanti, R.T dan B. Mudakir. 2013. Analisis Keuntungan dan Skala Usaha Perkebunan Kelapa Sawit Gerbang Serasan. Diponegoro Journal Of Economics 2 (1): 1-7 